\title{
Long-term daily monitoring of Saharan dust load over ocean using Meteosat ISCCP-B2 data 1. Methodology and preliminary results for 1983-1994 in the Mediterranean
}

\author{
C. Moulin and F. Guillard \\ Laboratoire de Modélisation du Climat et de l'Environnement, Direction des Sciences de la Matière, Commissariat à \\ l'Energie Atomique, Gif-Sur-Yvette, France

\section{F. Dulac and C. E. Lambert} \\ Centre des Faibles Radioactivités, Centre National de la Recherche Scientifique - Commissariat à l'Energie Atomique, \\ Gif-Sur-Yvette, France
}

\begin{abstract}
In this paper we describe a method to perform an accurate long-term monitoring of the optical thickness and mass column density of airborne desert dust over the Atlantic and the Mediterranean using Meteosat wideband solar (visible (VIS) plus near infrared) sensor. The dust load is retrieved using aerosol models and an Earth-atmosphere radiative transfer model. The method focuses on multiyear (from 1983 to 1994) daily retrieval of the atmospheric dust load using Meteosat low-resolution images prepared for the International Satellite Cloud Climatology Project (B2 format). We account for the variable calibrations, radiometric sensitivities, and spectral bands of the successive sensors (Meteosat 2 to Meteosat 5) as well as for the presence of marine background and stratospheric aerosols. We discuss the sensitivity of the method to different factors, and its accuracy is assessed in a companion paper. The results obtained include the daily geographical distribution of the dust load and the temporal variation of the dust load over marine areas. We illustrate and briefly discuss the results for the western Mediterranean and particularly for the Dynamique des Flux Atmosphériques en Méditerranée (DYFAMED) marine station in the Ligurian Sea. The dust transport mainly takes place during summer in this area. More than half a million metric tons of suspended dusts are occasionally observed over the western Mediterranean, and we observed an average of 16 dust events per year. At DYFAMED station the 11.5-year mean dust optical thickness is 0.11 , with annual means ranging from 0.055 in 1985 to 0.19 in 1992.
\end{abstract}

\section{Introduction}

The physics and chemistry of the marine atmosphere and the biogeochemical cycles in seawater are strongly influenced by the atmospheric transport and deposition of mineral aerosol particles which are massively exported from desert areas. The global mass of desert dust transported in the atmosphere is about one billion metric tons per year [D'Almeida, 1986]. Sahara and peripheral regions are the main source of soil-derived aerosols. All year long, African dusts are transported to the North Atlantic Ocean [Prospero, 1990] and Mediterranean Sea [Bergametti et al., 1989]. It is now well known that satellite observations of the sunlight reflected by the Earth-atmosphere system enable a relatively accurate retrieval of the vertically integrated dust aerosol content over the ocean in terms of optical thickness [e.g., Griggs, 1983]. Remote sensing by operational meteorological spaceborne sensors is suitable for the monitoring of large desert dust plumes which exhibit high temporal and spatial variability. Because of its location, Meteosat is particularly useful to study

Copyright 1997 by the American Geophysical Union.

Paper number 96JD02620.

0148-0227/97/96JD-02620\$09.00

\begin{abstract}
African dust transport over the northern hemisphere. Recent studies have been made using Meteosat observations in the solar spectrum visible (VIS channel) to retrieve the desert aerosol optical thickness over the tropical North Atlantic [Jankowiak and Tanré, 1992] and the Mediterranean Sea [Dulacet al., 1992]. Dulac et al. [1992] also derived the geographical distribution of the dust mass column density and the integrated dust mass over the western Mediterranean from full resolution images. The use of spatially degraded images, prepared for the International Satellite Cloud Climatology Project (ISCCP-B2 format) by the European Space Agency (ESA), Darmstadt, Germany, since mid-1983, allows a long-term monitoring of Saharan dust transport. Jankowiak and Tanré [1992] performed the first extensive use of Meteosat data for the retrieval of monthly dust transport frequencies over the tropical North Atlantic from daily Meteosat 2 ISCCP-B2 images from mid-1983 to mid-1988. In a recent paper, Swap et al. [1996] present a 3-year climatology of the Saharan dust transport derived from the Advanced Very High Resolution Radiometer (AVHRR) standard product of aerosol optical thickness over the world ocean [Rao et al., 1989]. However, this product has not been specifically designed for desert aerosol monitoring, and large errors on the aerosol optical thickness occur off Africa due to the use of a marine aerosol model in computations [Ignatov et al., 1995].
\end{abstract}


In this paper we present a method adapted from the former works of Jankowiak and Tanré [1992] and Dulac et al. [1992], which allows for a multiyear monitoring of daily dust optical thickness and mass column density over both the Mediterranean and the North Atlantic, using Meteosat B2-images from Meteosat 2,3,4, and 5. Thanks to a proper intercalibration of the different VIS sensors which followed Meteosat 2 [Moulin et al., 1996], we are able to perform a decadal survey of African dust export. In a companion paper (part 2), we present and analyze results from a comparison of Meteosat-derived aerosol optical thickness with Sun photometer ground measurements, and we discuss uncertainties of the method. Here we examine the sensitivity of the Meteosat VIS channel to atmospheric aerosols over marine areas by modeling the optical properties of the ground-atmosphere system. We apply the method to the monitoring of the atmospheric dust load over the western Mediterranean from June 1983 to December 1994, and we focus on the Dynamique des Flux Atmosphériques en MEDiterranee (DYFAMED) marine station between Corsica and France in the Ligurian Sea. This station is of special interest because atmospheric and marine sampling were performed for several years at or close to this station [Bergametti et al., 1989; BuatMénard and Lambert, 1993; Lloye-Pilot and Martin, 1996].

\section{Tools}

\subsection{Meteosat Sensors}

The European meteorological satellites from the Meteosat series have been providing data since 1978. Several platforms have been used in time: Meteosat 1 from 1978 to 1981 , Meteosat 2 from 1981 to 1988, Meteosat 3 till 1989, Meteosat 4 till 1993, and Meteosat 5 should be in use till some time in 1996. The Meteosat platform is geostationary, positioned over the Greenwich meridian and the equator at an altitude of about $36,000 \mathrm{~km}$. Meteosat scans the full Earth disk every half hour.

Meteosat provides images in three spectral bands: a solar (VIS) channel $(0.3-1.1 \mu \mathrm{m}$ ), a water vapor (WV) channel $(5.7-7.1 \mu \mathrm{m})$, and a thermal infrared (IR) channel (10.5-12.5 $\mu \mathrm{m})$. The spectral band of the VIS channel is centered around $\bar{\lambda}=0.70 \mu \mathrm{m}$ for all sensors. However, the band shape is fairly different from sensor to sensor, and these differences

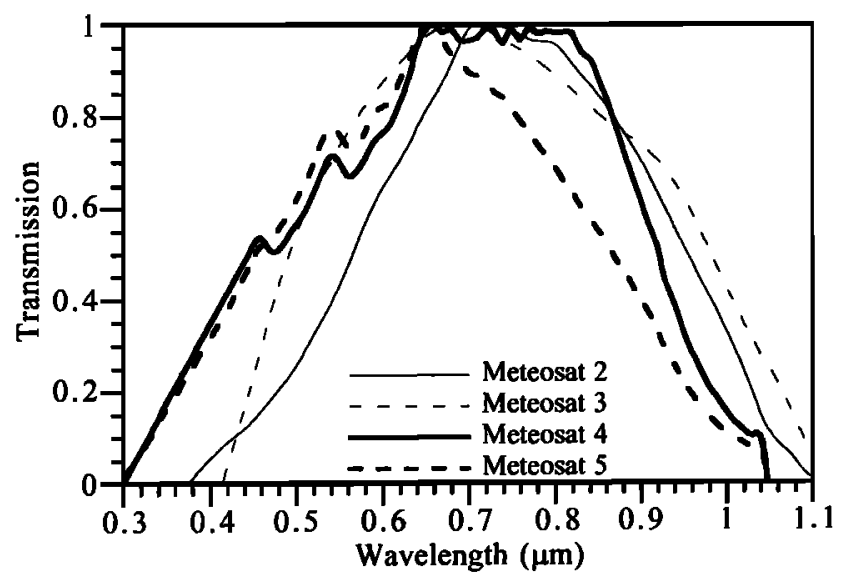

Figure 1. Spectral transmissions of the different Meteosat visible plus near-infrared (VIS) sensors [after Rossow et al., 1992]. should be taken into account when analyzing the signal for aerosol inversion. This is shown in Figure 1, which presents the transmission bands of the different VIS sensors. Meteosat 2 has a much lower sensitivity than the other sensors below $0.6 \mu \mathrm{m}$, i.e., in the domain of Rayleigh scattering by atmospheric gas molecules. At wavelengths above $0.8 \mu \mathrm{m}$, Meteosat 2,3 , and 4 are more sensitive than Meteosat 5 , and their sensitivity to gas absorption, mainly water vapor, is thus higher. On the contrary, Meteosat 4 and 5 are more sensitive to the scattering by gas molecules [Moulin et al., 1996].

The sensitivity of the various sensors mainly depends on the digitization. Before 1991 (Meteosat 4) the VIS signal was digitized in 64 levels, and the digital count produced by the sensor took values between 0 and 255 by steps of four counts (six significant bits on eight coded bits). With Meteosat 4 , the radiometric sensitivity was improved, and there were 255 levels (eight significant bits). Meteosat VIS data are obtained from the European Space Agency under several formats ranging from full resolution (hereinafter referred to as RTW) to ISCCP-B2 format.

A VIS image is composed of 2500 lines of 5000 pixels, with a pixel resolution of $2.5 \times 5.0 \mathrm{~km}$ at nadir. For B2 format, pixels are first averaged $2 \times 2$ from the original image, then, only one pixel over six and one line over six are retained. The B2 image size is $\mathbf{4 1 6}$ lines of $\mathbf{4 1 6}$ pixels, and the apparent resolution is $30 \mathrm{~km} \times 30 \mathrm{~km}$ at nadir. The temporal resolution is also reduced by keeping only one image every 3 hours. In this work we have only considered the B2 images of slot 24 (1130-1200 UT) in order to avoid Sun glint occurrences and to have sufficient light all year long over the whole Mediterranean and North Atlantic.

The radiance received by the sensor $L_{\text {sat }}$ is related to the numeric count by

$$
L_{\text {sat }}=a\left(N C-N C_{\theta}\right)
$$

where $a$ is the calibration coefficient, $N C$ the numeric count, and $N C_{0}$ the offset numeric count of the linear calibration. The VIS sensors are not calibrated in flight. Vicarious calibration campaigns, performed for Meteosat 2 and 4 [Koepke, 1983; Kriebel and Amann, 1993], provide limited information. We relied on the calibration monitoring performed by Moulin et al. [1996], which is based on a monitoring of desert and marine targets, taking into account the different spectral bands of the respective VIS sensors.

\subsection{Earth-Atmosphere Radiative Transfer Model}

We used an Earth-atmosphere radiative transfer model derived from the computer code "simulation of the satellite signal in the solar spectrum" (5S), available from the Laboratoire d'Optique Atmosphérique, Université des Sciences et Techniques de Lille, France [Tanré et al. 1990]. This radiative transfer model computes the satellite signal due to backscattering of solar light in the ground-atmosphere system, assuming a cloudless atmosphere. It includes analytical descriptions of the absorption by aerosol particles and atmospheric gases $\left(\mathrm{H}_{2} \mathrm{O}, \mathrm{O}_{3}, \mathrm{O}_{2}\right.$, and $\mathrm{CO}_{2}$ ), as well as descriptions of the scattering by gas molecules (Rayleigh scattering) and aerosols (Mie scattering). Input parameters are the geometrical and spectral conditions, atmospheric gaseous composition, aerosol optical properties and aerosol optical thickness at $0.55 \mu \mathrm{m}$, as well as the ground spectral reflectance. The outputs of the model are the direct and diffuse transmittances on the Sun-ground and ground-satellite paths, the spherical albedo of the atmosphere, the transmission factor related to the absorption by atmospheric components 
(aerosols, ozone, water vapor and oxygen), and the radiance at the satellite level. To simulate the satellite signal, the radiative transfer model takes also into account the spectral band of the considered sensor.

The basic radiative transfer equation of the model is

$$
\begin{aligned}
L_{s a t}\left(\theta_{S}, \theta_{V}, \phi\right) & =\frac{\mu_{S}}{\pi} \int_{\lambda_{1}}^{\lambda_{2}} E_{\lambda}^{S} T_{\lambda}^{g}\left[\rho_{\lambda}^{A}\left(\theta_{S}, \theta_{V}, \phi\right)\right. \\
& \left.+\rho_{\lambda}^{R}\left(\theta_{S}, \theta_{V}, \phi\right)+\frac{\rho_{\lambda} T_{\lambda}\left(\theta_{S}\right) T_{\lambda}\left(\theta_{V}\right)}{1-\rho_{\lambda} s_{\lambda}}\right] F_{\lambda} \mathrm{d} \lambda
\end{aligned}
$$

where $\lambda$ is the wavelength, $\theta_{S}$ and $\theta_{V}$ are the solar and zenithal viewing angles, $\phi$ is the azimuthal difference between incident and observation planes, and $\mu_{S}$ is the cosine of the zenithal solar angle. $E_{\lambda}^{s}$ is the solar irradiance at the top of the atmosphere; $\rho_{\lambda}^{A}, \rho_{\lambda}^{R}$, and $\rho_{\lambda}$ are the spectral reflectances of the aerosols, of the gas molecules, and of the surface, respectively; $T_{\lambda}$ is the atmospheric transmission (downward $T_{\lambda}\left(\theta_{S}\right)$ or upward $T_{\lambda}\left(\theta_{V}\right)$ ), and $T_{\lambda}^{g}$ is the atmospheric gaseous transmission; $s_{\lambda}$ is the spherical albedo of the atmosphere; and $F_{\lambda}$ is the sensor spectral response. Parameters $\lambda_{1}$ and $\lambda_{2}$ are the lower and the upper limits of the Meteosat spectral band and may be taken as 0.3 and $1.1 \mu \mathrm{m}$, respectively.

The 5S radiative transfer model computes the aerosol reflectance $\rho_{\lambda}^{A}$ using a parameterization of the multiple scattering [Tanré et al., 1990; Jankowiak and Tanré, 1992], given the aerosol optical thickness and spectral optical properties. However, for simplification, we used the single-scattering approximation to perform sensitivity tests, $\rho_{\lambda}^{A}$ being defined as

$$
\rho_{\lambda}^{A}\left(\theta_{S}, \theta_{V}, \phi\right)=\frac{\omega_{\lambda}^{A} P_{\lambda}^{A}(\chi) \tau_{\lambda}^{A}}{4 \mu_{S} \mu_{V}}
$$

where $\chi$ is the scattering angle; $\omega_{\lambda}^{A}$ and $P_{\lambda}^{A}$ are the single scattering albedo and the phase function of the aerosols, respectively; $\tau_{\lambda}^{A}$ is the aerosol optical thickness; and $\mu_{V}$ is the cosine of the zenithal viewing angle. The scattering angle is the angular difference between the incident and the scattered directions, depending on $\theta_{S}, \theta_{V}$, and $\phi$. The single-scattering albedo characterizes the absorption efficiency of the particles, and the phase function represents the scattering efficiency of the particles as a function of the scattering angle. Through the Mie theory the aerosol optical thickness $\tau_{\lambda}^{A}$ depends also on the quantity of aerosols in the atmospheric column, whereas $\omega_{\lambda}^{A}$ and $P_{\lambda}^{A}$ only depend on the aerosol model, i.e., the size distribution and complex refractive index. However, because the spectral variations of $\tau_{\lambda}^{A}$ are only related to the aerosol model, as for $\omega_{\lambda}^{A}$ and $P_{\lambda}^{A}$, the radiative transfer model requires only two parameters to compute $\rho_{\lambda}^{A}$ : the aerosol model and the aerosol optical thickness at a given wavelength. In the $5 \mathrm{~S}$ radiative transfer model, the reference wavelength is $0.55 \mu \mathrm{m}$, and we hereinafter will only refer to the aerosol optical thickness $\tau_{0.55}^{A}$.

\subsection{Parameters of the Radiative Transfer Model}

We initialized the radiative transfer model with the following parameters: the Rayleigh scattering and the gaseous transmission were computed using the U.S. Standard Atmosphere model of Mc Clatchey et al. [1971]; the clear seawater reflectance was estimated by Moulin et al. [1996] to obtain a satellite radiance coherent with the minimal numeric counts observed in the Mediterranean (the sea surface reflectance integrated over the spectral bands of Meteosat VIS sensors varies from 0.013 for Meteosat 2 to $\mathbf{0 . 0 1 8}$ for Meteosat 5). For aerosols the situation is more complicated. Indeed, the atmospheric aerosol is composed of various type of particles, with different sources and optical properties. We considered that over oceans, it may be separated in three main components: the stratospheric aerosol coming from volcanic eruptions, the background marine aerosol composed of sulphates and sea salts, and the desert dust.

For dust particles, we chose the background desert aeroso] model of Shettle [1984] with a specific complex refractive index of $1.50-i 0.010$ [Moulin et al., this issue]. The main characteristics of this model are summarized in Table 1. To estimate the desert dust optical thickness from the single Meteosat VIS measurement, we imposed the optical thickness of the other aerosols. The stratospheric contribution to the satellite radiance was derived from stratospheric optical thickness

\begin{tabular}{|c|c|c|c|c|c|}
\hline & Soot (BC) & Desert Dust (DD) & $75 \% \mathrm{H}_{2} \mathrm{SO}_{4}(\mathrm{HS})$ & Sea Salt (SS) & Water Soluble (WS) \\
\hline Reference & $W C P[1983]$ & Shettle $[1984]$ & D'Almeida et al. [1992] & $W C P[1983]$ & Shettle and Fenn [1979] \\
\hline Source & combustion & arid zones & volcanoes & sea surface & pollution, marine biology \\
\hline Type of particles & black carbon & mineral & stratospheric sulfates & sea salts & tropospheric sulfates \\
\hline Mean diameter, $\mu \mathrm{m}$ & 0.0236 & $\begin{array}{c}0.0020 \\
0.0436 \\
12.480\end{array}$ & 0.139 & 0.60 & 0.0285 \\
\hline $\begin{array}{l}\text { Geometric standard } \\
\text { deviation }\end{array}$ & 2.0 & $\begin{array}{l}2.13 \\
3.20 \\
1.89\end{array}$ & 1.86 & 2.51 & 2.24 \\
\hline Volumic mass, $\mathrm{g} \mathrm{cm}^{-3}$ & 2.3 & 2.5 & 1.7 & 2.2 & 1.8 \\
\hline Refractive index & $1.75-i 0.44$ & $1.50-i 0.01$ & $1.43-i 1.0 \times 10^{-8}$ & $1.381-i 4.26 \times 10^{-9}$ & $1.53-i 0.006$ \\
\hline$\omega_{0.70}^{A}$ & 0.16 & $0.89^{\mathrm{a}}$ & 1.00 & 1.00 & 0.95 \\
\hline$\sigma_{0.55}^{*}, \mathrm{~m}^{2} \mathrm{~g}^{-1}$ & 4.03 & $0.79^{\mathrm{a}}$ & 3.15 & 0.29 & 1.50 \\
\hline$a$ & 1.4 & 0.3 & 1.5 & -0.1 & 2.0 \\
\hline
\end{tabular}

Table 1. Description of the Tropospheric and Stratospheric Aerosol Models Used or Tested in This Work As Well As Their Optical Properties

The parameter $\omega_{0.70}^{A}$ is the single-scattering albedo at $\lambda=0.70 \mu \mathrm{m} ; \sigma_{0.5 s}^{*}$ is the specific extinction cross section at $0.55 \mu \mathrm{m}$; and $\alpha$ is the Angstrom exponent between 0.55 and $0.7 \mu \mathrm{m}$.

aRespective number proportions of the three modes: $54.21 \%, 45.79 \%, 3.86 \times 10^{-5} \%$. 
Table 2. Angular Variations of the Meteosat Slot 24 (11301200 UT) Observations Over Our Areas of Interest

\begin{tabular}{lccc}
\hline & $\theta_{S}$ & $\theta_{V}$ & $\phi$ \\
\hline 5S limits a & $60^{\circ}$ & $50^{\circ}$ & $\ldots$ \\
Mediterranean and Black Sea & $10^{\circ}-70^{\circ}$ & $40^{\circ}-65^{\circ}$ & $0^{\circ}-40^{\circ}$ \\
Atlantic & $15^{\circ}-70^{\circ}$ & $15^{\circ}-55^{\circ}$ & $0^{\circ}-70^{\circ}$ \\
\hline
\end{tabular}

a Tanré et al. [1990].

measurements, using the World Climate Program (WCP) [1983] model for stratospheric $\mathrm{H}_{2} \mathrm{SO}_{4}$ particles (Table 1). For the Mediterranean and North Atlantic we used monthly averaged measurements performed by lidar at the Observatoire de Haute Provence in southeastern France [Chazette et al., 1995], assuming that the volcanic aerosols were well zonally distributed. For the tropical Atlantic we built a table from available published data [Yue et al., 1991;Mc Cormick and Veiga, 1992; Jägeret al., 1995]. Monthly averaged stratospheric aerosol optical thickness vary between 0.0 and 0.2 with a maximum after the Mount Pinatubo eruption in September 1991. Since SAGE II data may underestimate volcanic optical thickness after eruptions because of a complete extinction of the Sun, we may have a bias in dust optical thickness in the tropics within months of the eruption of Mount Pinatubo. The sea-salt optical thickness is difficult to assess because its concentration is highly variable in time and space according to the surface wind. Therefore we reduced the background marine aerosol contribution to sulphate optical thicknesses. They were derived from monthly averaged, vertically integrated, sulphate concentrations from the model climatology of Langner and Rodhe [1991], using the tropospheric sulphate model from Shettle and Fenn [1979] reported in Table 1 . Monthly averaged marine sulphate optical thickness vary between 0.02 and 0.04 with a maximum in July and a minimum in November.

Meteosat observations sometimes go beyond the limits of validity of the $5 \mathrm{~S}$ radiative transfer model when solar or viewing angles become too large. This is particularly the case of geometric conditions in winter for limited areas such as the Azores region in the Atlantic and in the northeastern Mediterranean and the Black Sea. However, we did not perform any computations for angles overpassing the recommended limits by more than $10^{\circ}$. Table 2 shows the angular ranges encountered for the Mediterranean and Atlantic zones, for $\theta_{S}, \theta_{V}$, and $\phi$, as well as the corresponding recommended limits in the $5 \mathrm{~S}$ radiative transfer model. Jankowiak and Tanré [1992] have shown that the parameterization of the aerosol multiple scattering used in the $5 S$ radiative model is valid for dust optical thickness up to 2.0 , and Moulin et al. [this issue] found satisfactory results up to 1.65 when comparing coincident Meteosat-retrieved and Sun photometer-derived aerosol optical thicknesses.

\section{Method}

The retrieval of the aerosol optical thickness in the VIS spectral band of Meteosat is only possible over marine areas with low and fairly constant albedo. Indeed, the contribution from the atmosphere to the satellite signal is then dominant over the water surface. Moreover, within the atmospheric signal, only aerosol concentrations yield large variations in the radiance at the satellite level and thus of the numeric count $(N C)$ recorded by the sensor [Dulac et al., 1992]. We present here the main features of our method to compute the dust aerosol optical thickness at 0.55 $\mu \mathrm{m}\left(\tau_{0.55}^{A}\right)$ from the Meteosat VIS B2 pixel values.

1. We have masked the continents and islands. In addition, the pixels closest to the coast were discarded because of possible contamination from turbid waters with high reflectances.

2. We have used the specific character of dust clouds, which are spatially homogenous compared to water clouds [Coackley and Bretherton, 1982], to eliminate the latter. We retained a pixel only if the local standard deviation over a square of $3 \times 3$ pixels was lower than 4 [Jankowiak and Tanré, 1992]. However, to increase the number of available pixels, we saved a pixel with a local standard deviation larger than $\mathbf{4}$ when its numeric count was equal to a clear sky numeric count. Such pixels are generally near the coast or on the edge of a water cloud.

3. The numeric counts of the remaining marine pixels have been converted into satellite radiances $L_{\text {sat }}$ using the calibration coefficients given by Moulin et al. [1996].

4. To account for the contribution of the boundary layer marine aerosol and of the stratospheric particles to the aerosol optical thickness, we have subtracted their respective contributions to the satellite radiance to obtain a value of $L_{\text {sat }}$ only due to desert aerosols.

5 . We have used the $5 S$ model to retrieve the desert dust aerosol optical thickness at $0.55 \mu \mathrm{m}, \tau_{055}^{A}$. This was done iteratively in order to fit the value of $L_{\mathrm{s} a t}$ only due to desert aerosols. For long-term monitoring we imposed a null value to $\tau_{0.55}^{A}$ when it is found lower than the detection limit of Meteosat 2 (see section 4.1). For event or short-term studies we would not use this condition in order to keep the maximum information.

6. We have estimated the vertically integrated dust load $M_{d u s t}$ from the aerosol optical thickness using

$$
M_{\text {dust }}=\frac{\tau_{055}^{A}}{\sigma_{0.55}^{*}}
$$

where $\sigma_{055}^{*}$ is the specific extinction cross section at $0.55 \mu \mathrm{m}$ of the dust particles.

7. We have interpolated the value for the pixels which have been filtered to reconstruct the complete desert dust field over the Mediterranean Sea. We have used an inverse distance weighted method for the interpolation using the nearest unfiltered pixels. These pixels are iteratively searched by increasing the search area radius around the pixel to be interpolated until at least six valid pixels are found.

We applied this algorithm to one image per day between June 1983 and December 1994. First, we recorded the daily desert dust optical thickness and mass column density at different stations of particular interest in the Mediterranean and the Atlantic. For a given station, results were averaged from the unfiltered pixels in a square of $3 \times 3$ pixels. When no pixel is clear within the given area (cloudy day), we average the interpolated values for the site, provided that the nearest pixel used for interpolation is closer than $200 \mathrm{~km}$. We also performed spatial integration of $M_{\text {dust }}$ over all the marine pixels weighted by their respective surface in order to compute the total dust mass over selected marine areas. We decided to systematically discard images as too cloudy when less than 200 pixels (about 10\%) over the basin (Mediterranean or Atlantic) were available. We hypothesized that large-scale interpolation is possible since African dust transport is a large-scale phenomenon. It has been observed that dust particles are transported within warm and dry 
Table 3. Location of Sites and Zones of Interest

\begin{tabular}{cccccc}
\hline & \multicolumn{2}{c}{ Mediterranean } & & \multicolumn{2}{c}{ Northeastern Atlantic } \\
\cline { 2 - 3 } \cline { 5 - 6 } \cline { 5 - 6 } & Name & Location & & Name & Location \\
\hline Zone 1 & western Mediterranean & $5^{\circ} \mathrm{W}-20^{\circ} \mathrm{E}, 35^{\circ} \mathrm{N}-45^{\circ} \mathrm{N}$ & & midlatitude Atlantic & $30^{\circ} \mathrm{W}-0^{\circ}, 35^{\circ} \mathrm{N}-45^{\circ} \mathrm{N}$ \\
Zone 2 & eastem Mediterranean & $20^{\circ} \mathrm{E}-35^{\circ} \mathrm{E}, 30^{\circ} \mathrm{N}-40^{\circ} \mathrm{N}$ & & subtropical Atlantic & $35^{\circ} \mathrm{W}-5^{\circ} \mathrm{W}, 20^{\circ} \mathrm{N}-35^{\circ} \mathrm{N}$ \\
Zone 3 & Black Sea & $30^{\circ} \mathrm{E}-40^{\circ} \mathrm{E}, 40^{\circ} \mathrm{N}-45^{\circ} \mathrm{N}$ & & tropical Atlantic & $40^{\circ} \mathrm{W}-10^{\circ} \mathrm{W}, 5^{\circ} \mathrm{N}-20^{\circ} \mathrm{N}$ \\
Point I & Alboran Sea & $1.8^{\circ} \mathrm{W}, 35.6^{\circ} \mathrm{N}$ & & Azores Islands & $25.0^{\circ} \mathrm{W}, 37.0^{\circ} \mathrm{N}$ \\
Point 2 & Sardinia Island & $7.0^{\circ} \mathrm{E}, 39.2^{\circ} \mathrm{N}$ & & Canary Islands & $18.1^{\circ} \mathrm{W}, 26.9^{\circ} \mathrm{N}$ \\
Point 3 & DYFAMED station & $8.8^{\circ} \mathrm{E}, 42.6^{\circ} \mathrm{N}$ & & West point & $29.9^{\circ} \mathrm{W}, 25.0^{\circ} \mathrm{N}$ \\
Point 4 & Sicily Island & $13.5^{\circ} \mathrm{E}, 35.2^{\circ} \mathrm{N}$ & & Sal Island & \\
Point 5 & Crete Island & $22.3^{\circ} \mathrm{E}, 34.8^{\circ} \mathrm{N}$ & & South West point & $35.0^{\circ} \mathrm{W}, 17.1^{\circ} \mathrm{N}$ \\
Point 6 & Cyprus Island & $31.2^{\circ} \mathrm{E}, 34.6^{\circ} \mathrm{N}$ & & South point & $17.8^{\circ} \mathrm{W}, 8.1^{\circ} \mathrm{N}$ \\
\hline
\end{tabular}

air layers [Prospero and Carlson, 1981; Reiff et al., 1986], so that the water clouds can only be formed below or/and above these layers. This is confirmed by the few available lidar observations near Barbados [Talbot et al., 1986; Swap et al., 1992] and in the Azores region (J. Pelon et al., manuscript in preparation, 1996). This suggests a continuum of the dust plume despite variability in water clouds over a given region. In the same way, we interpolated the dust field over islands. It is obvious that the interpolation of the dust field is certainly one of the major source of errors for a given day, but time averages likely decrease these interpolation errors. This problem is particularly difficult to address and to quantify and is discussed in part 2 of this paper [Moulin et al., this issue]. The different zones and stations considered are shown in Table 3.

\section{Sensitivity of the Method}

We performed a number of tests to assess the sensitivity of our method. Results for the observation conditions of the DYFAMED marine station (Table 3) will be particularly illustrated.

\subsection{Detection Limit}

Figure 2 shows the variations of the radiance at the satellite level for an atmosphere free of aerosols, simulated using the radiative transfer model $5 \mathrm{~S}$. We compare here the results for Meteosat 2 and 4 targeting DYFAMED station. The variation of the signal is explained by variations in both geometrical conditions and solar irradiance. Solar irradiance over the western Mediterranean is maximum at the summer solstice when the solar zenith angle is minimum and decreases toward the winter solstice when the solar zenith angle increases. To this phenomenon a change in Rayleigh scattering efficiency with the scattering angle is superimposed. In the western Mediterranean the Rayleigh-scattering decreases at the summer solstice when the scattering angle is minimum $\left(150^{\circ}\right)$. Figure 2 also shows the influence of the spectral band on the satellite radiance. Indeed, there is about a factor of 2 difference between Meteosat 2 and 4 radiances, mainly caused by Rayleigh scattering around $0.35 \mu \mathrm{m}$ to which Meteosat 4 is much more sensitive (Figure 1). Figure 1 also plots the radiance limits between the successive Meteosat VIS numeric counts: 8 and 12 for Meteosat 2; 15 to 17 for Meteosat 4. The minimal numeric count for Meteosat 2 is always equal to 8; for Meteosat 4 it varies from 14 to 16 during the year.
We define the detection limit as the minimal aerosol optical thickness to increment the numeric count for clear sky over seawater, for example, generally from 8 to 12 for Meteosat 2 . In Figure 3 we used the radiative transfer model and the desert aerosol model of Shettle [1984] to derive this detection limit for the DYFAMED station. For Meteosat 2 the detection limit varies from 0.03 (in spring and fall) to $0.08-0.09$ (in summer and winter) and is anticorrelated with the clear sky radiances shown in Figure 2, because the aerosol optical thickness necessary to reach the numeric count 12 increases when the clear sky radiance decreases. Because of the better sensitivity of Meteosat 4 its detection limit is always lower than 0.06 , whatever the geometric conditions. Such variations imply that the minimal aerosol optical thickness, which can be detected, will vary with each sensor and throughout the year. This is unacceptable for our

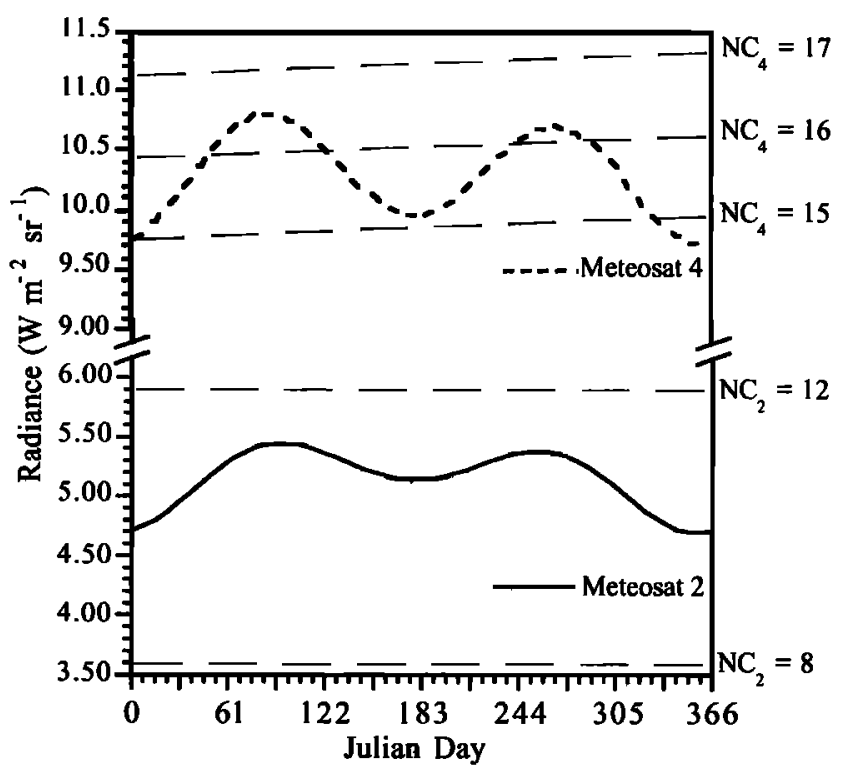

Figure 2. Variations of the Meteosat 2 (1986) and Meteosat 4 (1991) radiances for clear sky conditions (no aerosol) along the year at DYFAMED station, Ligurian Sea, $43.4^{\circ} \mathrm{N}-7.86^{\circ} \mathrm{E}$. The radiances necessary for the sensor to produce given numeric counts (NC) are plotted as dashed straight lines. For Meteosat 4 the drift of the calibration coefficient is of about $2 \% \mathrm{y}^{1}$ [Moulin et al., 1996]. 


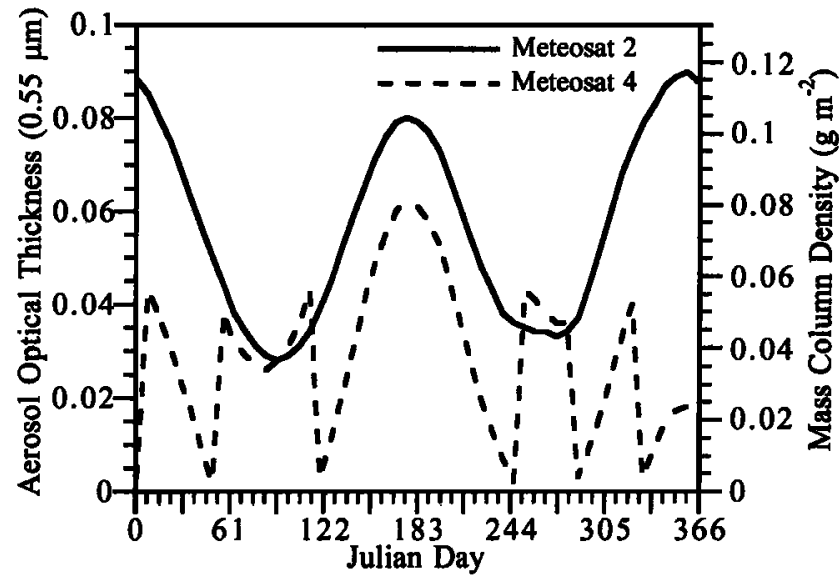

Figure 3. Variation along the year of the detection limit in desert dust optical thickness for Meteosat 2 and 4 at DYFAMED station.

longtime monitoring. Therefore we decided to impose a cutoff in terms of optical thickness, in order to have comparable desert dust estimates for a given pixel throughout the 12-year period. To achieve this, we calculated, for each pixel of the Mediterranean and the Atlantic, the worst detection limit along a whole year of Meteosat 2, the less sensitive sensor. We obtained the theoretical image, shown in Figure 4, of the minimal optical thickness which can be detected whatever the day in the year. Typically, this limit is within $0.05-0.15$ over the Mediterranean and ranges from 0.05 to 0.25 for the Atlantic. Because of a very high viewing zenith angle, the satellite radiance over the Black Sea exhibits a zone where the clear sky numeric count is incremented from 8 to 12 , yielding an abrupt increase of the detection limit. Figure 4 also shows that in a large part of our eastern tropical Atlantic zone (Table 3 ) the detection limit is larger than 0.25 . When we performed the long-term Meteosat data analyses, we set to zero the dust load of a given pixel, whatever the Meteosat sensor, when the optical thickness was smaller than this limit. For optical thickness above the detection limit, the value was not modified. The use of such a threshold yields a relative underestimate of the integrated dust mass but enables us to perform an objective comparison of results from different seasons and sensors.

\subsection{Aerosol Models}

The different tropospheric and stratospheric aerosol models used or tested in this work are described in Table 1. In addition to desert dust (DD), the tropospheric particles over marine areas are of three types: sulphates (WS) are very small particles, soluble in water, derived from gaseous sulphur compounds produced by the marine biological activity and the combustion of hydrocarbons; sea salts (SS) are large particles, composed of droplets lifted from the sea surface by the wind; black carbon (BC) is made of small absorbing particles produced by combustion. The stratospheric aerosol (HS) is composed of about $75 \%$ of sulphuric acid. It comes from photochemical oxidation of sulphur dioxide directly injected by explosive volcanic eruptions and of $\mathrm{COS}$, a relatively stable gas in the troposphere, derived from other gaseous sulphur compounds. Their residence time in the stratosphere is of about $8-12$ months [Chazette et al., 1995]. We do not consider the fact that just after an eruption, ashes are injected in the stratosphere because their

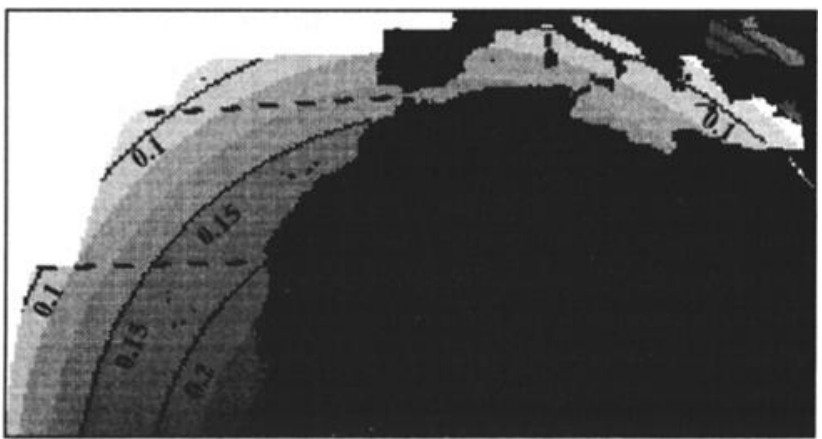

Figure 4. Worst detection limit (Meteosat 2) over the whole area (Mediterranean and Atlantic) in terms of desert dust aerosol optical depth. Dashed lines show geographic limits of the different zones defined in Table 3.

residence time is short. The main eruptions that affected the stratospheric aerosol content during our 12-year period were those of El Chichon (March - April 1982) and of Mount Pinatubo (June 1991). Spectral optical properties of the aerosols, such as the single-scattering albedo and the specific extinction cross section, were calculated from the relevant size distribution, particle density and refractive index (Table 1) using Mie theory [Van de Hulst, 1957]. The main assumptions are that particles are homogeneous and spherical and that their size distributions are lognormal. We integrated Mie calculations over a wide range of particle sizes: the lower size limit for integration (number median diameter divided by 3 times the geometric standard deviation) is such that only $0.13 \%$ of the total number of particles are smaller than this value, and the upper size limit (mass median diameter multiplied by 3 times the geometric standard deviation) is such that only $0.13 \%$ of the total mass is carried by larger particles. This ensures convergence of the computed aerosol optical properties even for widespread distributions.

The phase functions of these different aerosols at $\bar{\lambda}=0.70 \mu \mathrm{m}$, the spectral region of maximum VIS channel sensitivity, are shown in Figure 5. The aerosols composed of large particles (DD and SS) show much larger angle dependence of their phase function in the range of our Meteosat observations

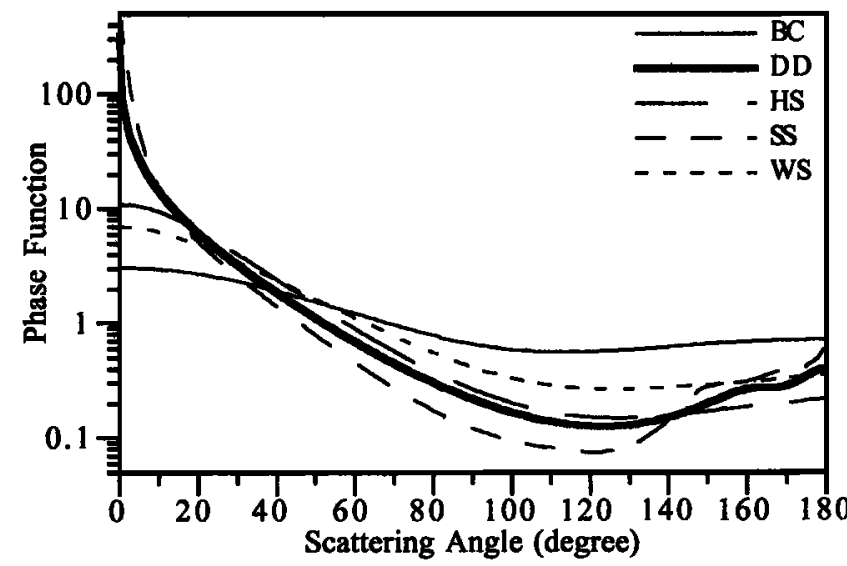

Figure 5. Phase functions at $\bar{\lambda}=0.70 \mu \mathrm{m}$ associated with the tropospheric and stratospheric aerosol models used or tested in this work (see Table 1): black carbon (BC), desert dust (DD), stratospheric aerosol (HS), sea salts (SS), and sulphates (WS). 


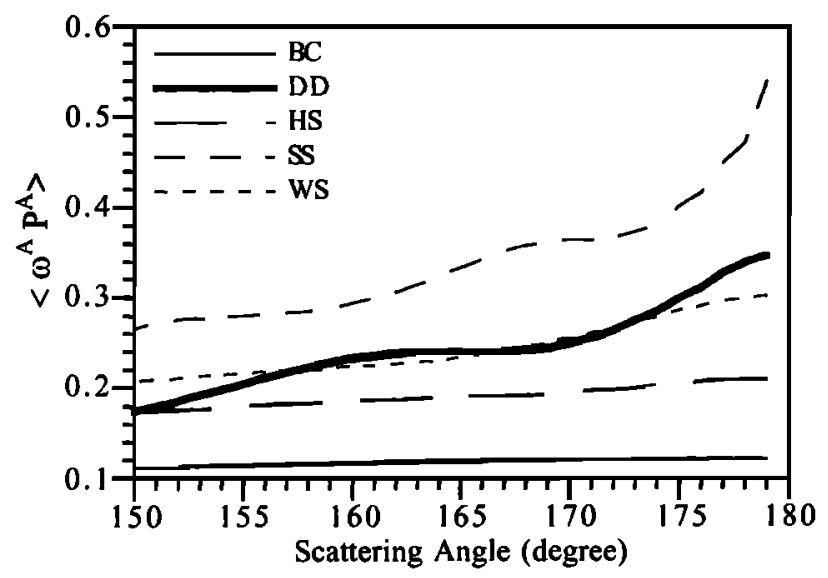

Figure 6. Variations of the product $\left\langle\omega^{A} P^{A}(\chi)\right\rangle$ integrated over the Meteosat 2 VIS spectral band, for a scattering angle $\chi$ varying between $150^{\circ}$ and $179^{\circ}$, and for the different aerosol models (see Table 1).

$\left(150^{\circ}-180^{\circ}\right)$ than smaller particle types. We tested the sensitivity of our inversion method to the aerosol optical properties using the variations of the product

$$
<\omega^{A} P^{A}(\chi)>=\frac{1}{\left(\lambda_{2}-\lambda_{1}\right)} \int_{\lambda_{1}}^{\lambda_{2}} \omega_{\lambda}^{A} P_{\lambda}^{A}(\chi) F_{\lambda} \mathrm{d} \lambda
$$

which represents the scattering efficiency of the aerosol model in the Meteosat spectral band for a given scattering angle. This term is suitable to observe the effect of the geometry variations on the satellite signal through equation (2) after spectral integration of equation (3). Indeed, for large values of this term, only a small variation of the optical thickness is sufficient to strongly increase the aerosol reflectance (equation (3)), and thus the satellite radiance. The evolution of this product with the scattering angle is shown in Figure 6 for the various aerosol models. One observes that sea salts (SS) lead to the largest values of the product, desert dust (DD) and sulphates (WS) lead to the same order of magnitude of values, and that they are much lower for stratospheric aerosol (HS) and soot (BC) models. The difference between the various aerosol models increases when the scattering angle increases, because large particles are much more efficient in backscattering than small particles. The BC model has the strongest absorption efficiency (low single-scattering albedo) which explains the low values of its product.

Figure 7 shows the variation of the radiance at the satellite level $\left(L_{s a t}\right)$ as a function of the optical thickness at $0.55 \mu \mathrm{m}$ for two geometries and for the various aerosol models used in Figure 6. This figure shows that the Meteosat signal is sensitive to the geometry of the measure and that the various aerosol models have a different behavior when the geometry changes, i.e., when the scattering angle changes. The absorbing black carbon aerosol has a negligible contribution to the Meteosat signal whatever the optical thickness and cannot be detected over seawater. The stratospheric and marine sulphates have a constant and nonnegligible contribution to the satellite radiance, justifying our correction before the desert aerosol optical thickness retrieval. Sea salts have a behavior very close to the desert aerosols. Their contribution to the Meteosat signal might then be important, but we did not take them into account in our method because, contrary to sulphates and stratospheric aerosols, we have no appropriate information on their variability which depends on wind stress, and because their optical thickness is generally low. Results on background marine aerosols (including sea salts) obtained by Chiapello [1996] at Sal Island, Cape Verde, indicate that their optical thickness is likely to be around 0.05 . Measured optical thickness in the marine boundary layer of the North Atlantic [Hoppel et al., 1990] and of the western Mediterranean Sea [Haggerty et al., 1990; Moulin et al., this issue] ranges between 0.04 and 0.2 with a strong daily variability. Therefore our climatological background marine aerosol optical thickness, which ranges between 0.02 and 0.04 , appears underestimated. It enables us to account only for the low-frequency variations of the marine aerosol contribution.

\subsection{Radiometric Sensitivity}

For optical thickness larger than the detection limit, the digitization becomes a major source of error, mainly for Meteosat 2 and 3 which have a numerical count increment of 4 units. Indeed, because the calibration of Meteosat sensors was performed by means of a statistical comparison of calculated radiances and measured numeric counts [Moulin et al., 1996], the radiance computed from a given numeric count is only a mean value. The actual radiance may then range between the radiance calculated for $N C \pm 2$ for Meteosat 2 and 3 and $N C \pm 0.5$ for Meteosat 4 and 5 . This uncertainty on the radiance computed from a numeric count yields an uncertainty on the determination of the optical thickness for a given pixel and a given day.

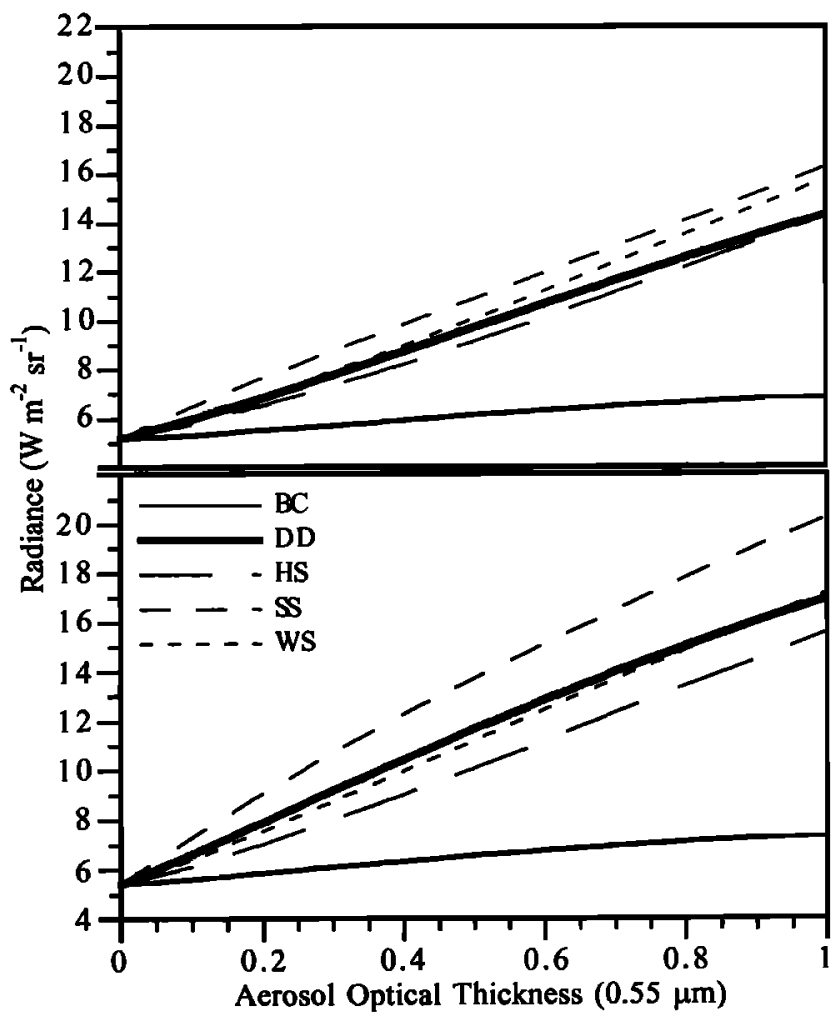

Figure 7. Variations of the Meteosat 2 radiance for different geometries at the DYFAMED station, as a function of the aerosol optical thickness. Aerosol models are as in Figure 6. (top) Summer solstice observation; (bottom) autumn equinox observation. 


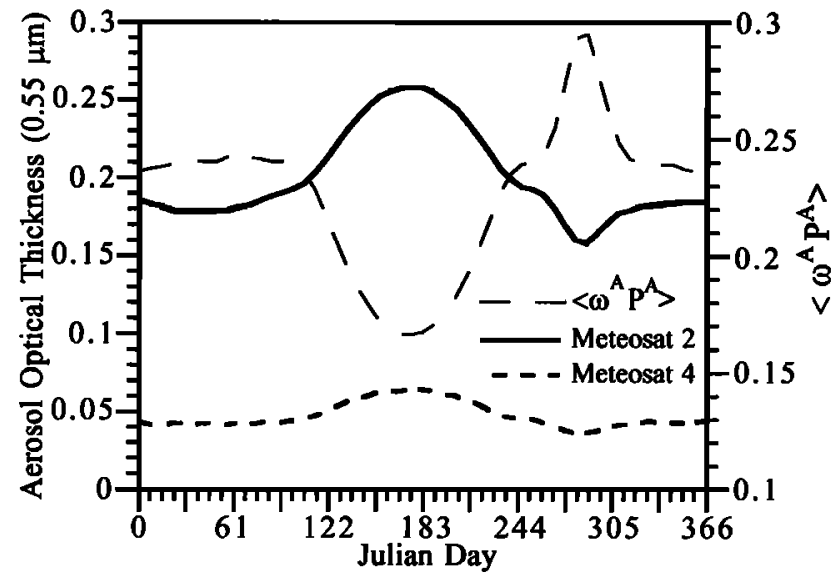

Figure 8. All-year-long sensitivity in aerosol optical thickness for Meteosat 2 and 4 shown, together with $\left\langle\omega^{A} P^{A}(\chi)>\right.$ (see text), at the DYFAMED station.

We defined the sensor sensitivity as the minimal aerosol optical thickness necessary to increment the numeric count once from the first numeric count above the detection limit (e.g., generally from 12 to 16 for Meteosat 2). Figure 8 shows that the sensitivity at DYFAMED station varies between 0.16 and 0.26 for Meteosat 2 and remains about constant at 0.04-0.06 for Meteosat 4. In Figure 8 we also observe the variations of $<\omega^{A} P^{A}(\chi)>$ which varies by a factor of 2 during the year and is anticorrelated to the sensitivity. The annual variation of the scattering angle over our Atlantic and Mediterranean areas vary between $150^{\circ}$ and $180^{\circ}$. The lowest sensitivity, i.e., the maximum optical thickness necessary to increment the numeric count, occurs in summer when the scattering angle and thus $<\omega^{A} P^{A}(\chi)>$, is low, around $150^{\circ}$. The highest sensitivity corresponds to the maximum of $\left\langle\omega^{A} P^{A}(\chi)\right\rangle$ in autumn, for a scattering angle of about $175^{\circ}$.

\subsection{Image Degradation}

To validate our long-term analysis of degraded B2 images, we compared the results with those obtained from the full resolution (RTW) data analyzed using the same method. Indeed, the sampling and averaging applied to RTW images to obtain B2 images could lead to a loss of information. The analysis for the

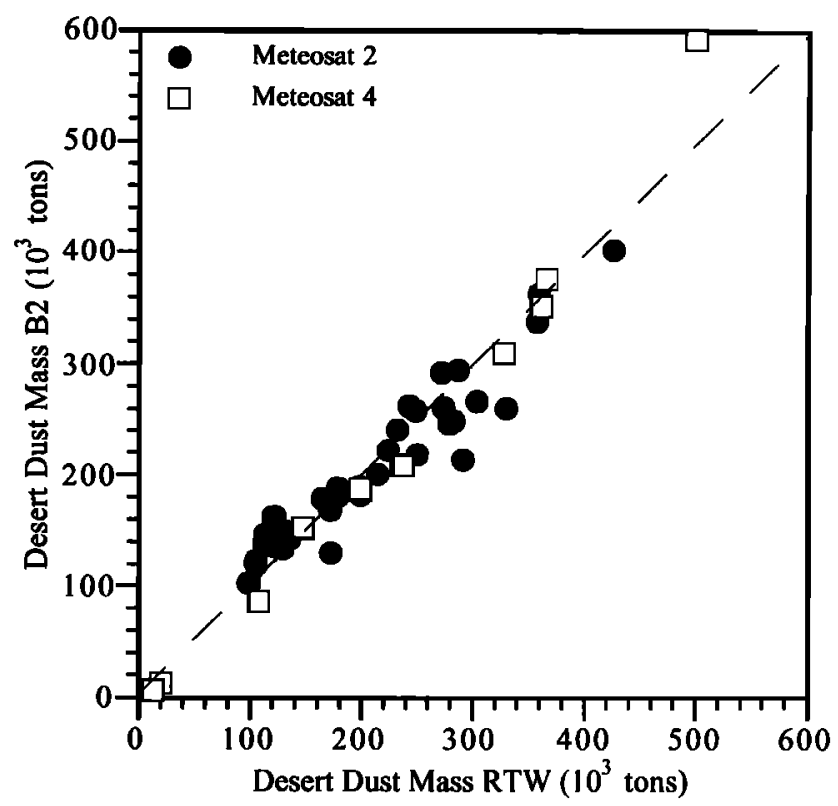

Figure 9. Comparison of estimates of the desert dust mass integrated over the western Mediterranean, obtained with ISCCP-B2 and full resolution data (35 Meteosat 2 images and 10 Meteosat 4 images).

two formats differs only by the cloud elimination criteria. For RTW images we used the test established by Dulac et al. [1992] which allows a maximum local standard deviation of $\sqrt{8}$ over a square of $3 \times 3$ pixels and hereinafter eliminates a pixel which has not at least eight clear adjacent pixels. We have analyzed a set of 35 Meteosat 2 images in 1985 and 1986 and 10 Meteosat 4 images in 1988. Figure 9 shows the comparison between the B2 and RTW estimates of desert dust masses integrated over the western Mediterranean for 45 images. The linear regression analysis (confidence level $>99.9 \%$ ) shows that there is no significant difference between the two results: the average ratio between $B 2$ and RTW estimates is $0.99 \pm 0.02$. This validates the use of degraded images for a long-term study, knowing that there is a difference of roughly 1 order of magnitude in computer time and memory requirements between the analysis of B2 and RTW. However, in the case of relatively high cloud coverage over the basin, such as in winter, the B2 images which have a

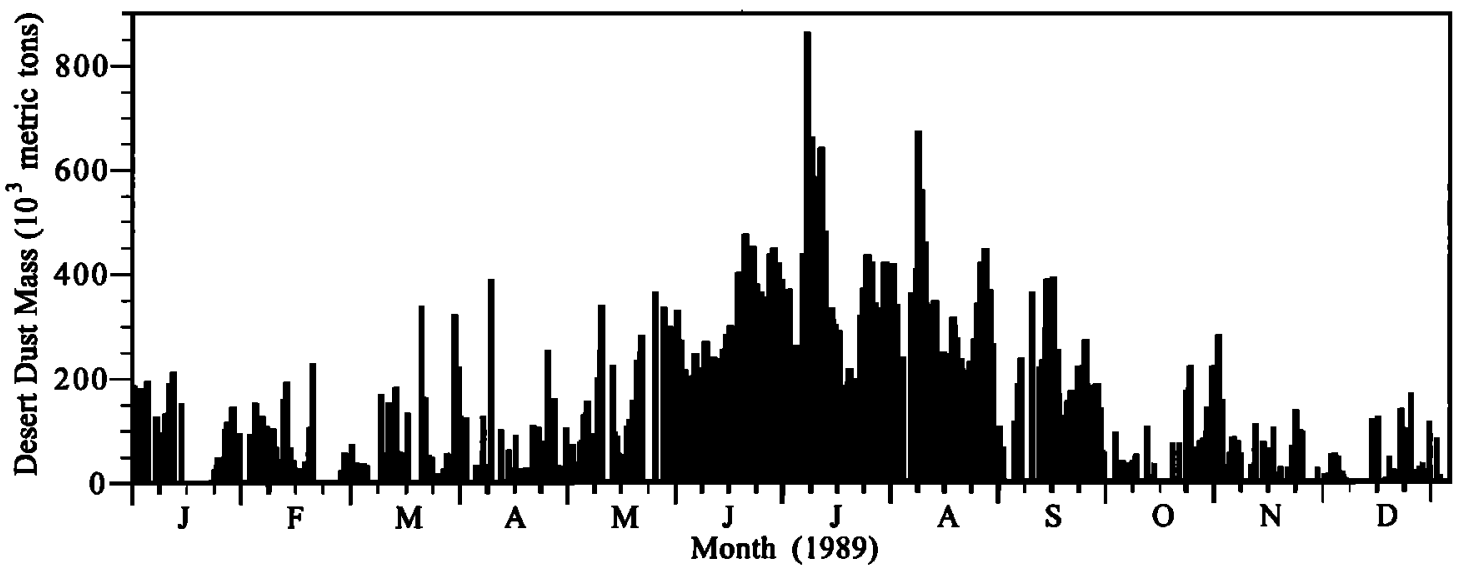

Figure 10. Total suspended desert dust mass over the western Mediterranean, as results from the analysis of daily 1989 images. 

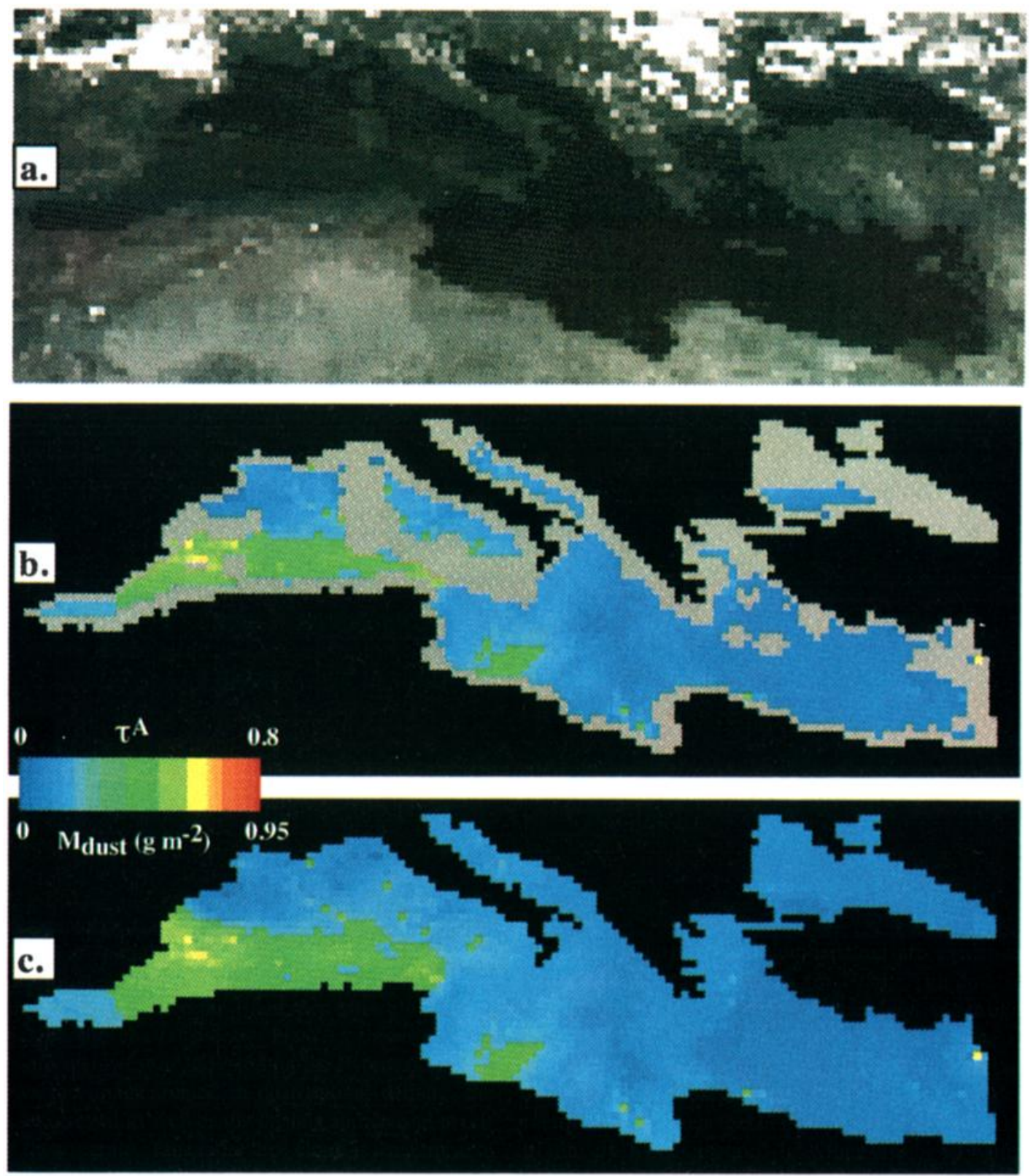

Plate 1. Analysed Meteosat image for a dust event over the Mediterranean (July 6, 1994): (a) B2 raw data, (b) retrieved optical depth for clear sky pixels, and (c) interpolated field of the dust mass column density.

small number of pixels are generally rejected as too cloudy by our validity criteria, whereas the corresponding RTW image could sometimes be properly analyzed.

\section{Results}

One analyzed image, July 6, 1994, is shown in Plate 1. Because of the poor spatial resolution of Meteosat B2 images, there were at most 1750 marine pixels remaining in the Mediterranean basin and 200 in the Black Sea after elimination of the main island and coastal pixels. Plate la shows the raw image; clouds are seen west of Italy and on the Pyrenean region. Plate $1 \mathrm{~b}$ shows the image treated in dust optical density; the cloudy pixels are greyed as well as the islands and coastal pixels eliminated by the program. One large dust cloud is seen north of Algeria and is linked to the synoptic meteorological situation. A depression in central Algeria (centered at about $27^{\circ} \mathrm{N}$ ) is developing July 4 and 5 characterized by $15 \mathrm{~m} \mathrm{~s}^{-1}$ winds. Dust is transported northward and is detected over the Mediterranean Sea on the July 6, where the dust cloud extends from Algeria to Spain. A smaller, more local dust plume is detected out of Lybia. Plate lc shows the dust optical density after interpolation. The large-scale pattern of the dust plume seems well recovered by the interpolation.

One year of data is shown in Figure 10. The variability for the western Mediterranean in 1989 and particularly the differences beween wintertime and summertime are evidenced. Table 4 summarizes monthly results for 1989 . The dust is transported mostly during the dry season: June, July, and August represent about $50 \%$ of the total transport. There is a factor of 6 between the richest month (average daily mass of $375 \times 10^{3}$ metric tons in July) and the poorest month (average daily mass of $58 \times 10^{3}$ metric tons in November). One observes in Figure 10 an increase of the dust background: less than $100 \times 10^{3}$ metric tons of suspended dust in winter and more than $200 \times 10^{3}$ metric tons in summertime. This is due to the accumulation of dust during the dry season when there is no removal of particles by rain. To this background are superimposed peaks of intense transport, with up 
Table 4. Monthly Statistics of the 1989 Meteosat B2 Data for the Western Mediterranean

\begin{tabular}{lrcc}
\hline \multicolumn{1}{c}{ Month } & $\begin{array}{c}\text { Mean Dust } \\
\text { Mass, } 10^{3} \text { tons }\end{array}$ & $\begin{array}{c}\text { Number of } \\
\text { Days Retained }\end{array}$ & $\begin{array}{c}\text { Mean Percentage of } \\
\text { Interpolated Pixels }\end{array}$ \\
\hline January & 122 & 20 & 79 \\
February & 92 & 19 & 72 \\
March & 96 & 25 & 65 \\
April & 97 & 21 & 74 \\
May & 178 & 23 & 67 \\
June & 300 & 29 & 65 \\
July & 375 & 30 & 58 \\
August & 306 & 28 & 61 \\
September & 202 & 24 & 75 \\
October & 95 & 23 & 75 \\
November & 58 & 23 & 80 \\
December & 62 & 21 & 74 \\
\hline
\end{tabular}

See Figure 10.

to $850 \times 10^{3}$ metric tons of suspended dust, occurring during brief events (two days to a week at most). In addition to the mean dust mass, Table 4 shows that because of the cloud coverage the number of available clear sky pixels decreases during winter, yielding a lower number of valid days per month (from $\mathbf{3 0}$ in July to about 20 in wintertime) and a larger number of interpolated pixels for these remaining days (from $58 \%$ in July to $80 \%$ in November). This implies that our results are more uncertain during fall and winter than during spring and summer.

Twelve years of vertically integrated dust load are shown in Figure 11 at the DYFAMED station. A square area of about 100 $\mathrm{km}$ by $100 \mathrm{~km}$ between the French coast and Corsica was analyzed daily. One observes a high daily, seasonal, and interannual variability of the dust plumes. At a daily timescale the strong variability of the dust load shows the sporadicity of the dust transport over the western basin. As in 1994 for the whole basin, the most important and frequent dust plumes appear at DYFAMED point between late spring and summertime: the whole period is then more elevated in background dust than in wintertime. Although our results may be biased by a larger number of cloudy days in winter than in summertime, seasonal variation is so strong that it overcomes any bias due to undersampling in winter. The year-to-year variability of the dust transport is evidence by an increase of both background and peak dust loads. The average dust mass column density for $\mathbf{3 0 0 0}$ days representing the available data for 11 complete years is 0.13 $\mathrm{g} \mathrm{m}^{-2}$ (i.e., about 0.11 in dust optical thickness); 6 years are in average higher than this value and 5 years lower. Table 5 shows statistics of the results for the 12 years, including average desert dust optical thickness and mass column density: the most dusty periods are 1983-1984 and 1992; the year less rich in dust is 1987. This interannual variability is in good agreement with other observations: the frequency of Saharan dust transport was observed to be maximum in 1984 both over the tropical Atlantic in the period 1984-1988 [Jankowiak, 1992] and over northwestern Africa during the period 1984-1991 [N'Doumé, 1993]. The second period with large dust transport is centered on the year 1992. Whereas this year was affected by the Pinatubo eruption, yielding a larger uncertainty on our results, Figure 11 shows that the whole period 1989-1993 was characterized by relatively large dust transport. Moreover, there is no apparent important change in the baseline in the second part of 1992 , which indicates that our stratospheric correction is rather good. In addition, 3 years of dust concentrations obtained at Sal Island, Cape Verde, indicate more intense transport in 1992 as compared with 1993 and 1994 [Chiapello et al., 1995]. As discussed by Dulac et al. [1996], the correspondence between the observed interannual variability of the dust transport and the drought periods in Africa strongly support that the magnitude of Saharan dust export is driven by climatic conditions in source areas. From the data plotted in Figure 11 we looked for the number of peaks by defining a peak as a day with concentrations above the monthly mean and higher than the two preceding and the two following days. The total number of peaks detected at DYFAMED over the study period is 181 , i.e., about 16 significant dust events per year on average. This is consistent with existing ground-based monitoring of dust concentrations of Bergametti et al. [1989], who report 21 African dust events from aerosol ground measurements in northwestern Corsica, close to the DYFAMED station, during 13 months between April 1985 and April 1986. In addition, original data from Bergametti [1987] show about $30 \mathrm{Si}$ concentration peaks between mid February 1985 and late April 1986. Among these, only five events were missed by our Meteosat survey: four of them (in

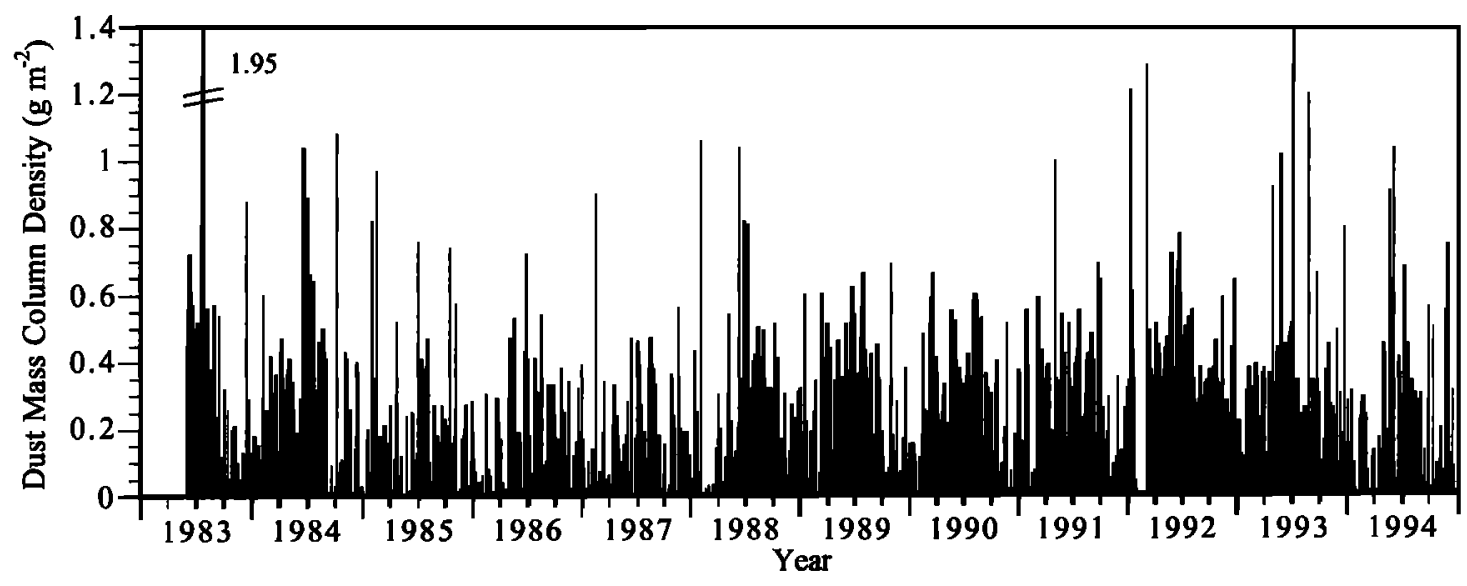

Figure 11. Results from the analysis of 12 years (June 1983 to December 1994) of daily B2 images for the DYFAMED station. 
Table 5. Yearly Statistics of the Analysis of 12 years of Meteosat B2 Data at the DYFAMED Station

\begin{tabular}{lccccc}
\hline & & & \multicolumn{3}{c}{ Number of Days } \\
\cline { 4 - 6 } Year & Mean Dust Optical Depth at $0.55 \mu \mathrm{m}$ & Mean Dust Mass, $\mathrm{g} \mathrm{m}^{-2}$ & Retained & Cloudy & Untreated \\
\hline $1983^{\mathrm{a}}$ & 0.176 & 0.222 & 160 & 39 & 15 \\
1984 & 0.111 & 0.140 & 258 & 88 & 20 \\
1985 & 0.054 & 0.082 & 269 & 69 & 27 \\
1986 & 0.065 & 0.080 & 277 & 67 & 21 \\
1987 & 0.060 & 0.076 & 275 & 75 & 15 \\
1988 & 0.084 & 0.106 & 272 & 66 & 28 \\
1989 & 0.123 & 0.155 & 280 & 61 & 24 \\
1990 & 0.119 & 0.150 & 288 & 69 & 8 \\
1991 & 0.106 & 0.134 & 292 & 62 & 11 \\
1992 & 0.188 & 0.238 & 263 & 63 & 40 \\
1993 & 0.144 & 0.182 & 262 & 89 & 14 \\
1994 & 0.098 & 0.123 & 265 & 98 & 2 \\
$1984-1994$ & 0.106 & 0.133 & 3001 & 807 & 210 \\
\hline
\end{tabular}

See Figure 11

aJune-December period only.

May and November 1985 and in February and March 1986) because of the cloud cover, and the other one (in August 1985) probably because the aerosol optical thickness was too low in the Ligurian Sea to be detected, as a small dust plume can be seen arriving farther west.

\section{Conclusion}

We developed a procedure, based on a radiative transfer model and aerosol optical properties, to estimate the African dust optical thickness and mass column density from Meteosat ISCCP-B2 images. Our aim was to perform a multiyear (19831994) survey of the African dust transport over the Mediterranean and the northeastern Atlantic. We took into account the different characteristics of the various Meteosat sensors (Meteosat 2 to 5), and we corrected the Meteosat signal for the contributions of stratospheric aerosols due to major volcanic eruptions and of tropospheric sulphates. To enable a long-term comparison of the results, we defined a detection limit, constant over the whole 12-year period, for each pixel. Finally, we checked that the low resolution of B2 images did not affect the integrated dust mass estimates. Accuracy and validation of our method are described in paper 2 . Results constitute a powerful data bank to monitor the African dust transport and to estimate the total mass of terrigeneous material exported from Africa as well as the importance of the deposition of mineral aerosol input to sea surface waters. The preliminary results show that the Saharan dust transport over the western Mediterranean is always maximum during summertime and that its intensity is highly variable from year to year. Over this basin, about two thirds of the annual amount of suspended dust are found in summer, and more than half a million metric tons of dust can be occasionally found. At the DYFAMED station in the Ligurian Sea, the 11.5-year average dust optical depth is about 0.11 , corresponding to an average mass column density of $0.13 \mathrm{~g} \mathrm{~m}^{-2}$, and yearly means differ from this climatological average by a factor of up to 2 . On the average, we observed 16 dust events per year. Our results provide unequaled constraints for dust transport modeling [Nickovic and Dobricic, 1996; Balkanski et al, 1996; Schulz et al., 1996] and will allow a long-term study of the impact of African dusts on the radiative budget at a regional scale.

Acknowledgments. We are grateful to Uffe Hansson from Stockholm University and M. Kanakidou from CFR who provided the sulphate data. We acknowledge the kind help of F. Maignan and S. Poirier with computing mysteries and $\mathrm{D}$. Lardieri, who participated to our testing experiments. This work is part of a close collaboration between the LMCE and the CFR and was supported by the French Commissariat à l'Energie Atomique (CEA) and Centre National de la Recherche Scientifique (CNRS). Additional support was provided by INSU/CNRS and the French Ministère de l'Environnement first through the "ATP Aérosols Désertiques" and then through the research project "Erosion Eolienne en Régions Arides et Semi-Arides" of the "Programme Environnement/section Phase Atmosphérique des Grands Cycles Biogéochimiques". C.E. Lambert and F. Dulac would like to express their gratitude to the CEA for the computing facilities and the generous hospitality provided by the LMCE. Authors acknowledge the two anonymous reviewers of the paper for valuable comments. This is contribution 378 from the LMCE and 1870 from the CFR.

\section{References}

Balkanski, Y., M. Schulz, B. Marticorena, G. Bergametti, W. Guelle, F. Dulac, C. Moulin, and C. E. Lambert, Importance of the source term and of the size distribution to model the mineral dust cycle, in The Impact of Desert Dust Across the Mediterranean, edited by $\mathbf{S}$. Guerzoni and R. Chester, pp. 69-76, Kluwer Acad., Norwell, Mass., 1996.

Bergametti, G., Apports de matière par voie atmosphérique à la Méditerranée occidentale: Aspects géochimiques et météorologiques, Ph.D. thesis, Univ. of Paris 7, 1987.

Bergametti, G., L. Gomes, E. Remoudaki, M. Desbois, D. Martin, and P. Buat-Ménard, Present transport and deposition patterns of African dusts to the northwestern Mediterranean, in Paleoclimatology and Paleometeorology: Modern and Past Patterns of Global Atmospheric Transport, edited by M. Leinen and M. Sarnthein, pp. 227-251, Kluwer Acad., Norwell, Mass., 1989.

Buat-Ménard, P., and C. E. Lambert, Overview of the DYFAMED program, Ann. Inst. Océanogr. Paris, 69, 1993. 
Chazette, P., C. David, J. Lefrère, S. Godin, J. Pelon, and G. Mégie, Comparative lidar study of the optical, geometrical, and dynamical properties of stratospheric postvolcanic aerosols, following the eruptions of El Chichon and Mount Pinatubo, J. Geophys. Res., 100, 23,195-23,207, 1995.

Chiapello, I., Les aérosols atmosphériques au-dessus de l'Atlantique nord tropical: Approche physico-chimique et météorologique. Evaluation de la contribution des différentes espèces à l'épaisseur optique en aérosol, Ph.D. thesis, Univ. of Paris 7, 1996.

Chiapello, I., G. Bergametti, L. Gomes, B. Chatenet, F. Dulac, J. Pimenta, and E. Santos Suares, An additional low layer transport of Sahelian and Saharan dust over the northeastern tropical Atlantic, Geophys. Res. Lett., 22(23), 3191-3194, 1995.

Coackley, J. A., Jr., and F. P. Bretherton, Cloud cover from highresolution scanner data: Detecting and allowing for partially filled fields of view, J. Geophys. Res., 87, 4917-4932, 1982.

D'Almeida, G. A., A model for Saharan dust transport, J. Clim. Appl. Meteorol., 24, 903-916, 1986.

Dulac, F., D. Tanré, G. Bergametti, P. Buat-Ménard, M. Desbois, and D. Sutton, Assessment of the African airborne dust mass over the Mediterranean Sea using Meteosat data. J. Geophys. Res., 97, 2489 2506, 1992.

Dulac, F., C. Moulin, C. E. Lambert, F. Guillard, J. Poitou, W. Guelle, C. Quétel, X. Schneider, and U. Ezat, Quantitative remote sensing of African dust transport to the Mediterranean, in The Impact of Desert Dust Across the Mediterranean, edited by S. Guerzoni and R. Chester, pp. 25-49, Kluwer Acad., Norwell, Mass., 1996.

Griggs, M., Satellite measurements of tropospheric aerosols, Adv. Space Res., 2, 109-118, 1983.

Haggerty, J. A., P. A. Durkee, and B. J. Wattle, A comparison of surface and satellite-derived aerosol measurements in the western Mediterranean, J. Geophys. Res., 95, 1547-1557, 1990.

Hoppel, W. A., J. W. Fitzgerald, G. M. Frick, R. E. Larson, and E. J. Mack, Aerosol size distributions and optical properties found in the marine boundary layer over the Atlantic Ocean, J. Geophys. Res., 95, 3659-3686, 1990

Ignatov, A. M., L. L. Stowe, S. M. Sakerin, and G. K. Korotaev, Validation of the NOAA/NESDIS satellite aerosol product over the North Atlantic in 1989, J. Geophys. Res., 100,5123-5132, 1995.

Jäger, H., O. Uchino, T. Nagai, T. Fujimoto, V. Freudenthaler, and F. Homburg, Ground-based remote sensing of the decaying of the Pinatubo eruption cloud at 3 northem hemisphere sites, Geophys. Res. Lett., 22(5), 607-610, 1995.

Jankowiak, I., Surveillance des aérosols désertiques à partir de l'imagerie Meteosat et estimation de leur impact radiatif, Ph.D. thesis, Univ. of Lille, Lille, France, 1992.

Jankowiak, I., and D. Tanré, Satellite climatology of Saharan dust outbreaks: Method and preliminary results, J. Clim., 5, 646-656, 1992.

Koepke, P., Calibration of the VIS-channel of Meteosat-2, Adv. Space Res., 2, 93-96, 1983.

Kriebel, K. T., and V. Amann, Vicarious calibration of the Meteosat visible channel, J. Atmos. Oceanic Technol., J0, 225-232, 1993.

Langner, J., and H. Rodhe, A global three-dimensional model of the tropospheric sulphur cycle, J. Atmos. Chem., 13, 255-263, 1991.

Lloye-Pilot, M. D., and J. M. Martin, Saharan dust input to the western Mediterranean: An eleven years record in Corsica, in The Impact of Desert Dust Across the Mediterranean, edited by S. Guerzoni and R. Chester, pp. 191-200, Kluwer Acad., Norwell, Mass., 1996.

Mc Clatchey, R. A., R. W. Fenn, J. E. A. Selby, F. E. Volz, and J. S. Garing, Optical properties of the atmosphere, Rep. AFCRL-TR-7I0279, Environ. Res. Pap. 354, Air Force Cambridge Res. Lab., Bedford, Mass., 1971.

Mc Cormick, M. P., and R. E. Veiga, Sage II measurements of early Pinatubo aerosols, Geophys. Res. Lett., 19(2), 155-158, 1992.

Moulin, C., C. E. Lambert, J. Poitou, and F. Dulac, Long-term (19831994) calibration of the Meteosat solar (VIS) channel using desert and marine targets, Int. J. Remote Sens., I7(6), 1183-1200, 1996.

Moulin, C., F. Dulac, C. E. Lambert, P. Chazette, I. Jankowiak, B. Chatenet, and F. Lavenu, Long-term daily monitoring of Saharan dust load over marine areas using Meteosat ISCCP-B2 data, 2, Accuracy of the method and validation using Sun photometer measurements, $J$. Geophys. Res., this issue.
N'Doumé, C. T., Traitement de l'imagerie Meteosat IR pour l'observation des aérosols désertiques au dessus de l'Afrique: Optimisation, validation et application à l'ètablissement des distributions spatiotemporelles, Ph.D. thesis, Univ. of Lille, Lille, France, 1993.

Nickovic, S, and S. Dobricic, A model for long-range transport of desert dust, Mon. Weather Rev., in press, 1996.

Prospero, J. M., and T. B. Carlson, Saharan air outbreaks over the tropical North Atlantic, Pure Appl. Geophys., 119, 677-691, 1981

Prospero, J. M., Mineral-aerosol transport to the North Atlantic and North Pacific: The impact of African and Asian sources, in The Long-Range Atmospheric Transport of Natural and Contaminant Substances, edited by A. H. Knap, pp. 59-86, Kluwer Acad., Norwell, Mass., 1990.

Rao, C. R. N., L. L. Stowe, and E. P. McClain, Remote sensing of aerosols over the oceans using AVHRR data-Theory, practice and applications, Int. J. Remote Sens., I0, 743-749, 1989.

Reiff, J., G. S. Forbes, F. T. M. Spieksma, and J. J. Reynders, African dust reaching northwestern Europe: $A$ case study to verify trajectory calculations, J. Clim. Appl. Meteorol., 25, 1543-1567, 1986.

Rossow, W. B., Y. Desormeaux, C. L. Brest, and A. Walker, Intemational Satellite Cloud Climatology Project (ISCCP): Radiance calibration, Rep. TD-520, World Clim. Res. Programme, World Meteorol. Organ., Geneva, 1992.

Schulz, M., Y. Balkanski, W. Guelle, F. Dulac, C. Moulin, and C. E. Lambert, Model components necessary to capture a dust plume pattern over the Mediterranean Sea, in The Impact of Desert Dust Across the Mediterranean, edited by S. Guerzoni and R. Chester, pp. 51-58, Kluwer Acad., Norwell, Mass., 1996.

Shettle, E. P., Optical and radiative properties of a desert aerosol model, in Proceedings of the Symposium on Radiation in the Atmosphere, edited by G. Fiocco, pp. 74-77, A. Deepak, Hampton, Va., 1984.

Shettle, E. P., and R. W. Fenn, Models for the aerosols of the lower atmosphere and the effects of humidity variations on their optical properties, Rep. AFGL-TR-79-02/4. Environ. Rer. Pap. 675, Air Force Geophys. Lab., Hanscom Air Force Base, Mass., 1979.

Swap, R., M. Garstang, S. Greco, R. Talbot, and P. Kallberg, Saharan dust in the Amazon basin, Tellus, Ser. B, 44, 133-149, 1992.

Swap, R., S. Ulanski, M. Cobbett, and M. Garstang, Temporal and spatial characteristics of Saharan dust outbreaks, J. Geophys. Res., 101, 4205-4220, 1996.

Talbot R. W., R. C. Harriss, E. V. Browell, G. L. Gregory, D. I. Sebacher, and S. M. Beck, Distribution and geochemistry of aerosols in the tropical North Atlantic troposphere: Relationship to Saharan dust, J. Geophys. Res., 91, 5173-5182, 1986.

Tanré, D., C. Derro, P. Duhaut, M. Herman, J. J. Morcrette, J. Perbos, and P. Y. Deschamps, Description of a computer code to simulate the satellite in the solar spectrum: The $5 \mathrm{~S}$ code, Int. J. Remote Sens., 11 , 659-668, 1990.

Van de Hulst, H. C., Light Scattering by Small Particles, John Wiley, New York, 1957.

Viollier, M., Télédétection des concentrations de seston et pigments chlorophylliens contenus dans l'océan, Ph.D. thesis, Univ. of Lille, Lille, France, 1980.

World Climate Programme (WCP), Aerosols and Their Climatic Effects, Ser. Rep. 55, edited by A. Deepak and H. E. Gerber, Int. Counc. Sci. Unions and World Meteorol. Organ., Geneva, 1983.

Yue, G. K., M. P. Mc Cormick, and E. W. Chiou, Stratospheric aerosol optical depth observed by the Stratospheric Aerosol and Gas Experiment II: Decay of the El Chichon and Ruiz volcanic perturbations, J. Geophys. Res., 96, 5209-5219, 1991.

F. Guillard and C. Moulin (corresponding author), Laboratoire de Modélisation du Climat et de l'Environnement, Commissariat à l'Energie Atomique, Centre d'Etudes de Saclay, l'Orme des Merisiers 709, F91191 Gif sur Yvette Cedex, France. (e-mail: cyril.moulin@cea.fr)

F. Dulac and C.E. Lambert, Centre des Faibles Radioactivités, Centre National de la Recherche Scientifique - Commissariat à l'Energie Atomique, F-91198 Gif-Sur-Yvette Cedex, France. (e-mail: dulac@cea.fr; lambertc@prolix.saclay.cea.fr)

(Received February 29, 1996; revised August 1, 1996; accepted August 7, 1996.) 